\title{
A Refined Model to Predict Near-Term US Real GDP Growth
}

\author{
Manuel G. Russon \\ St. John's University \\ Vipul Bansal \\ St. John's University
}

\begin{abstract}
The Gross Domestic Product (GDP) is defined as the monetary value of all the finished goods and services produced within a country's borders in a specific time period. Real GDP (RGDP) is GDP adjusted for the cost of living and is computed as Nominal GDP divided by a deflator. It is largely taken to be a measure of the economy of a country's well-being, while year over year percentage changes in the RGDP measure economic growth (RGDPG. This research investigates the possibility that, in addition to trend, inflation may be a determinant of RGDPG. Specially, inflation is found to be a leading determinant having a negative influence.
\end{abstract}

Keywords: gross domestic product, consumer price index, trend

\section{INTRODUCTION}

The Gross Domestic Product (GDP) is defined as the monetary value of all the finished goods and services produced within a country's borders in a specific time period. Real GDP (RGDP) is GDP adjusted for the cost of living and is computed as Nominal GDP divided by a deflator. RGDP is largely taken to be a measure of the economy of a country's well-being. RGDP Growth (RGDPG) is computed as year over year percentage changes in RGDP and measures economic growth.

Recent research by the authors noted that large scale econometric models of RGDP growth can be very complex, often incorporating hundreds of linear and non-linear equations. Variables used to quantify monetary, fiscal and taxation policy, the international sector, population and demographic variables, productivity and capital expenditures, geopolitical, etc. are included to estimate their respective effects on RGDPG. Rising above the complexity of the large-scale models, that research presented a high-level look at US RGDP growth and concluded that there has been a statistically significant downward trend since 1946. Current levels of RGDPG are forecasted to be in the range of $2 \%$ per year. This is quite apart from administration forecasts of RGDPG levels in the 3-4\% range.

This research digs a bit deeper beyond the statistically significant trend down in RGDPG found in the afore-mentioned research, yet still maintaining a high level, top down perspective, to identify factors affecting RGDPG. Specifically, this research identifies the contribution of inflation as it affects RGDPG. Macroeconomic theorists have argued whether inflation is a cause or consequence of RGDPG, the relationship - be it positive or negative - and whatever that relationship is, whether it is leading, lagging, or 
a coincident indicator. This research looks at the lag structure of inflation and RGDPG and concludes that inflation is a negative leading indicator of RGDPG.

\section{DATA AND ANALYSIS}

Annual non-seasonally adjusted time series data for RGDP and the Consumer Price Index was obtained from the Federal Reserve Bank of St. Louis data website for the years 1946 to 2018 ending 12/31. Hence there are 73 annual observations.

A time series plot of RGDP is shown in Fig. 1 and shows RGDP to be increasing at a basically constant rate. The time series plot percentage change in RGDPG shown in Fig. 2 shows that the growth trend is down but volatile. The histogram displayed in Fig. 3, shows the extent of the volatility with annualized RGDPG ranging from $-4 \%$ to $8 \%$.

FIGURE 1

TSPLOT REAL GDP

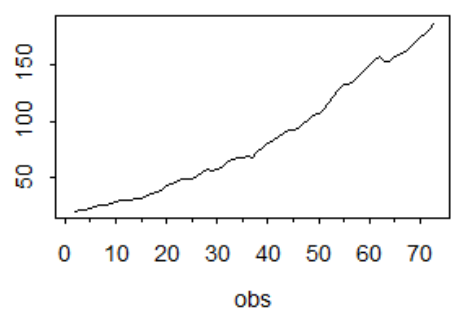

FIGURE 2

TSPLOT \% CHNG REAL GDP

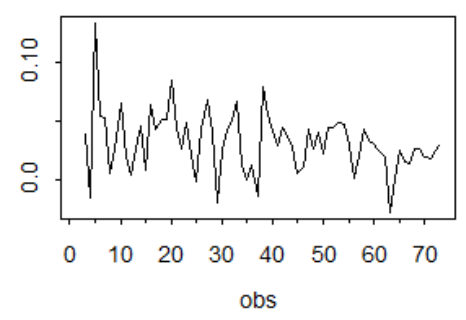

FIGURE 3

HIST. \% CHNG REAL GDP

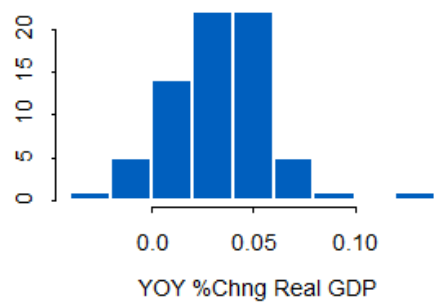


FIGURE 4

TSPLOT CPI

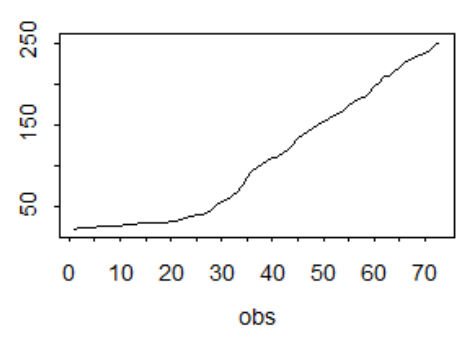

FIGURE 5

TSPLOT 12M INFLATION

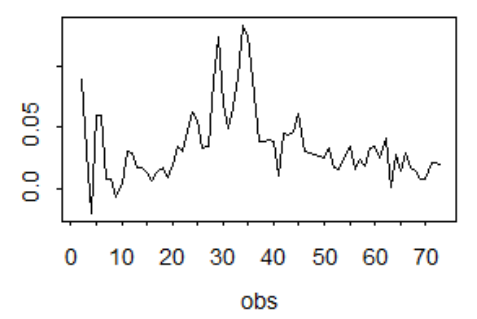

FIGURE 6

HIST. 12M INFLATION

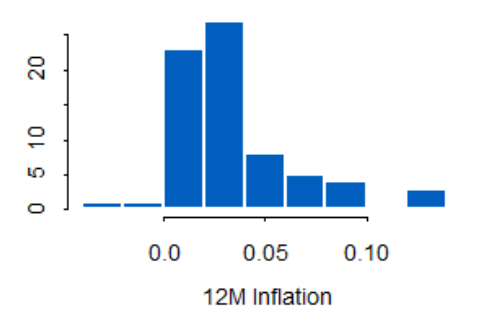

A time series plot of CPI is shown in Fig. 4 and shows CPI increasing at a generally linear rate. But as seen in the time series plot in Fig. 5, the YOY inflation rate is decreasing. The histogram displayed in Fig. 6 shows the distribution to be skewed to the right with annualized Inflation ranging from 3\% to $14 \%$.

Table 1 displays descriptive statistics for annual percent change in RGDP and Inflation Rate. Note that the aggregate mean postwar RGDPG is $3.2 \%$ with a standard deviation of $2.6 \%$, and the postwar Inflation rate is $3.5 \%$ with a standard deviation of $2.9 \%$.

TABLE 1

DESCRIPTIVE STATISTICS

\begin{tabular}{|l|l||l||l|l||l||l|l||l||l||l||}
\hline & Minimum & Q1 & Mean & Med. & Q3 & Max. & St. Dev. & Skew. & Kurt. & n \\
\hline PCRGDP & -0.028 & 0.019 & 0.032 & 0.029 & 0.045 & 0.134 & 0.026 & 0.668 & 2.792 & 73 \\
\hline Inflation & -0.021 & 0.017 & 0.035 & 0.029 & 0.044 & 0.133 & 0.029 & 1.466 & 2.530 & 73 \\
\hline
\end{tabular}


Table 2 displays a correlation matrix of RGDPG with trend and inflation. The correlations are weak. The negative correlation of -.267 of RGDPG is noteworthy and a focus of this research.

TABLE 2

CORRELATION MATRIX

\begin{tabular}{|l||l||l||l||}
\hline & Real GDP growth (RGDPG) & Observations & inflation \\
\hline \hline Real GDP Growth (RGDPG) & 1.000 & -0.267 & -0.048 \\
\hline Observations & -0.267 & 1.000 & -0.083 \\
\hline inflation & -0.048 & -0.83 & 1.000 \\
\hline
\end{tabular}

Table 3 displays correlations current level of RGDPG with lead and lag correlations of YOY Inflation.

TABLE 3

LAG CORRELATIONS OF INFLATION WITH RGDPG

\begin{tabular}{|l||l|l|l|l||l|l|l|l|l|}
\hline \multicolumn{1}{|c|}{} & \multicolumn{4}{c||}{ Leading Correlations } & \multicolumn{4}{c|}{ Lagging Correlations } \\
\hline \hline & 4 & 3 & 2 & 1 & 0 & -1 & -2 & -3 & -4 \\
\hline Corr DF & 0.235 & 0.127 & -0.161 & -0.327 & -0.048 & 0.09 & 0.227 & 0.078 & 0.052 \\
\hline
\end{tabular}

Note that the correlation of one period leading value of Inflation period with RGDPG is -.327 . While that correlation is not particularly strong it is the highest negative correlation and suggests that inflation leading 1 period might have an impact on RGDP the subsequent period. Figs. 7, 8 and 9 display scatterplots of RGDPG vs YOY Inflation for 1 period leading, current Inflation and Inflation lagged 1 year.

FIGURE 7

RGDPG V 12M INFLA

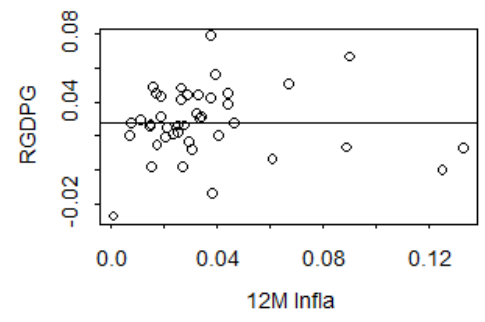

FIGURE 8

RGDPG V 12M INFLA, LAG1

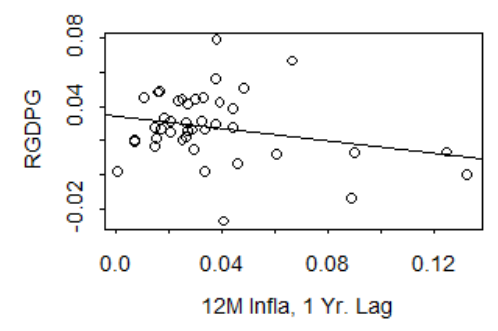


FIGURE 9

RGDPG V 12M INFLA, LAG2

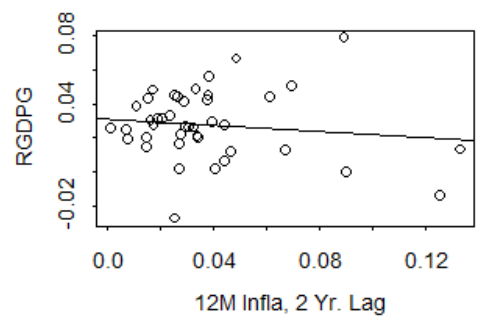

The negative correlation coefficient seen in Table 3 between RGDPG and InflaLag1 is visually apparent in Fig. 8. The suspicion is that higher inflation leads to lower RDGPG in the subsequent year.

Eqns. 1, 2 and 3 display a functional specification, population regression line and sample regression line of models to estimate RGDPG as a function of time and inflation at Lag i.

- Eqn. 1 RGDPG = f(Trend, Inflation(i))

- Eqn. 2 RGDPG $=\mathrm{a}+\mathrm{b}_{\text {obs }} *$ Trend $+\mathrm{b}_{\text {inflation }}$ Inflation(i) $+\mathrm{e}$

- Eqn. 3 RGDPG $=a+b_{\text {obs }} *$ Trend $+b_{\text {inflation }} *$ Inflation(i) $+e$

Tables 4, 5 and 6 display the results of the multiple linear regression trend analysis of RGDPG on trend and inflation with 0,1 and 2 lags, respectively.

TABLE 4

REGRESSION OF REAL GDP GROWTH WITH TREND AND INFLATION

\begin{tabular}{|c||c||c|c|c|}
\hline Variable & Constant & Trend & Inflation Lag 0 & \\
\hline \hline Coefficient & .0428 & -.0004 & -.0607 & \\
\hline t-stat & 9.54 & -2.99 & -.57 & \\
\hline p-value & .00 & .02 & -.56 & \\
\hline F=2.72 & F-Sig $=.07$ & $\mathrm{R}-\mathrm{Sq}=.077$ & $\mathrm{Adj} \mathrm{R}-\mathrm{Sq}=.0496$ & $\mathrm{Df}=65$ \\
\hline
\end{tabular}

TABLE 5

REGRESSION OF REAL GDP GROWTH WITH TREND AND INFLATION

\begin{tabular}{|c||c||c|c|c|}
\hline Variable & Constant & Trend & Inflation Lag 1 & \\
\hline \hline Coefficient & .0575 & -.0004 & -.3211 & \\
\hline t-stat & 7.96 & -2.6 & -3.25 & \\
\hline p-value & .00 & .01 & .18 & \\
\hline F= 8.27 & F-Sig $=.07$ & $\mathrm{R}-\mathrm{Sq}=.201$ & $\mathrm{Adj} \mathrm{R}-\mathrm{Sq}=.19$ & $\mathrm{Df}=65$ \\
\hline
\end{tabular}

TABLE 6

REGRESSION OF REAL GDP GROWTH WITH TREND AND INFLATION

\begin{tabular}{|c||c||c|c|c|}
\hline Variable & Constant & Trend & Inflation Lag 2 & \\
\hline \hline Coefficient & .0519 & -.0004 & -.1638 & \\
\hline t-stat & 6.72 & -2.41 & -1.59 & \\
\hline p-value & .00 & .02 & -.11 & \\
\hline F =3.91 & F-Sig $=.03$ & $\mathrm{R}-\mathrm{Sq}=.11$ & Adj R-Sq $=.173$ & $\mathrm{Df}=65$ \\
\hline
\end{tabular}


Only the F statistic of 8.27 for the equation with Lag 1 in Table 5 is significant at the $5 \%$ level. The coefficient of determination (R-squared) indicates that $20.1 \%$ of the variation in the RGDPG can be explained by variation in the Trend and Inflation lagged 1 period. The t-statistics for both Trend and Inflation are statistically significant at the $1 \%$ level of significance. The other models are not statistically significant and the explanatory power of each is quite low. As the model with inflation leading 1 period yields the greatest significance and explanatory power, we deem Model 2 which includes Inflation leading 1 period to be superior.

The histogram of the residuals which appears in Fig. 10 is normally distributed indicating a correctly specified model. The actual v predicted values of RGDPG which appears in Fig. 11 also displays evidence of a correctly specified model.

\section{FIGURE 10 \\ HIST. OF RESIDUALS}

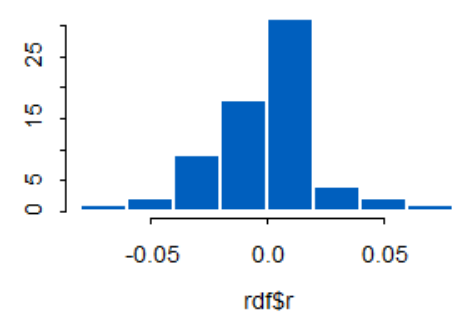

FIGURE 11

ACT. V PRED. RGDPG

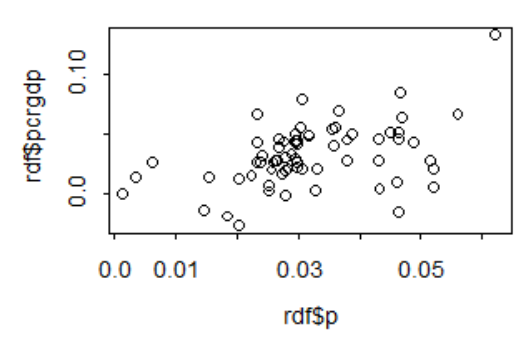

FIGURE 12

TSPLOT OF ACT. AND PRED RGDPG

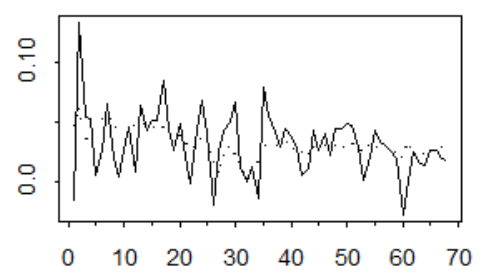

\section{DISCUSSION}

The coefficient for inflation one period ahead is statistically significant negative. That the variable precedes the current level of RGDPG indicates a high possibility for causality. Public policy should be oriented to keeping inflation low in order to keep RGDPG higher. It follows that the supply side paradigm 
of the 1980s and 1990s which increased capacity to keep inflation low in order to keep RGDPG high was correct. The low inflation we witness in 2018 and 2019 is buoying the current levels of RGDPG.

The statistically significant coefficient for trend should be of concern. It indicates RGDPG is trend down and shows no indication of abating, on average and holding other things - like inflation - constant. The source of the trend down should be investigated.

\section{CONCLUSIONS}

Large scale econometric models are useful for macroeconomic policy making in both the long and short runs. Indeed, the models might be used to optimize policy prescriptions from a static or dynamic perspective. On the other hand, this research takes a macro, top down view of US Real GDP Growth. This top-down analysis clearly points to a statistically significant decreasing trend in RGDP growth since 1946 and argues that this trend will continue. Also, the research finds that RGDPG is negatively sensitive to one year leads of the inflation rate. Hence, while short term or transitory growth rates might occur due to short term fiscal stimulus or other exogenous factors, the research points to a diminishing growth rate in RGDP in trend and that the growth rate is muted by high inflation rates with a one-year lag.

Further research should further investigate what is behind the trend downward. But as political and socio-economic pressures are always present for a higher RGDP growth rate, public policy should be oriented to keeping inflation low.

\section{REFERENCES}

Aiken, M. (2000). Forecasting the United States gross domestic product with the neural network. Journal of International Information Management, 9(1).

Potter, S.M. (1995). A Nonlinear Approach to US GNP. Journal of Applied Econometrics, 10(2).

Stock, J.H., \& Watson, M.W. (1999). Business Cycle Fluctuations in US Macroeconomic Time Series. Handbook of Macroeconomics, 1(Part A), 3-64. 